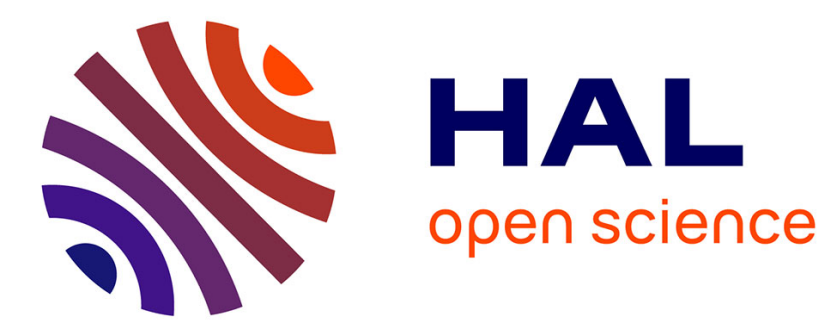

\title{
Global sensitivity analysis applied to a contamination assessment model of listeria monocytogenes in cold smoked salmon at consumption
}

\author{
Mariem Ellouze, Jean-Pierre Gauchi, Jean-Christophe Augustin
}

\section{To cite this version:}

Mariem Ellouze, Jean-Pierre Gauchi, Jean-Christophe Augustin. Global sensitivity analysis applied to a contamination assessment model of listeria monocytogenes in cold smoked salmon at consumption. Risk Analysis, 2010, 30 (5), pp.841-852. 10.1111/j.1539-6924.2010.01380.x . hal-02660485

\section{HAL Id: hal-02660485 \\ https://hal.inrae.fr/hal-02660485}

Submitted on 30 May 2020

HAL is a multi-disciplinary open access archive for the deposit and dissemination of scientific research documents, whether they are published or not. The documents may come from teaching and research institutions in France or abroad, or from public or private research centers.
L'archive ouverte pluridisciplinaire HAL, est destinée au dépôt et à la diffusion de documents scientifiques de niveau recherche, publiés ou non, émanant des établissements d'enseignement et de recherche français ou étrangers, des laboratoires publics ou privés. 


\title{
Global Sensitivity Analysis Applied to a Contamination Assessment Model of Listeria monocytogenes in Cold Smoked Salmon at Consumption
}

\author{
Mariem Ellouze, ${ }^{1-3, *}$ Jean-Pierre Gauchi, $^{2}$ and Jean-Christophe Augustin ${ }^{1}$
}

\begin{abstract}
In this study, a variance-based global sensitivity analysis method was first applied to a contamination assessment model of Listeria monocytogenes in cold smoked vacuum packed salmon at consumption. The impact of the choice of the modeling approach (populational or cellular) of the primary and secondary models as well as the effect of their associated input factors on the final contamination level was investigated. Results provided a subset of important factors, including the food water activity, its storage temperature, and duration in the domestic refrigerator. A refined sensitivity analysis was then performed to rank the important factors, tested over narrower ranges of variation corresponding to their current distributions, using three techniques: ANOVA, Spearman correlation coefficient, and partial least squares regression. Finally, the refined sensitivity analysis was used to rank the important factors.
\end{abstract}

KEY WORDS: Listeria monocytogenes; quantitative microbial risk assessment; sensitivity analysis

\section{INTRODUCTION}

Over the last years, quantitative microbial risk assessment (QMRA) has become an important tool for food safety, however criticized as an extremely data hungry and time consuming method. ${ }^{(1)}$ In fact, simple and deterministic approaches are now put aside and a large variety of complexities can be found with very extensive and stochastic models. Indeed, it can be tempting to include every phenomenon that could be of relevance, but this could lead to overparameterized models. ${ }^{(2)}$ Sensitivity analysis (SA) can help solve this issue by eliminating the less influential factors. SA is defined as the study of how the out-

\footnotetext{
${ }^{1}$ Unité MASQ, Ecole Nationale Vétérinaire d'Alfort, MaisonsAlfort Cedex, France.

${ }^{2}$ Unité MIA (UR341), INRA, Jouy en Josas, France.

${ }^{3}$ CRYOLOG SA, Nantes, France.

*Address correspondence to Mariem Ellouze, 7, Avenue du Général de Gaulle, Pôle HQSA, Maisons Alfort 94700, France; mellouze@vet-alfort.fr.
}

put uncertainty of a model can be apportioned to different sources of uncertainty in the model input. ${ }^{(3)}$ Several SA methods have been previously used in QMRA (e.g., ANOVA, Spearman correlation coefficient $)^{(4,5)}$ but these methods seem to be poorly adapted to complex and nonlinear models like those encountered in QMRA. Variance-based methods are commonly recognized in the statistical field and have been previously used in several scientific areas (e.g., ecology, chemistry, agronomy). Their application to microbiological modeling issues will represent a major breakthrough in QMRA. These methods proved to be useful to explore models over different combinations of input values to study how the variance of the output depends on the inputs and can be decomposed accordingly. ${ }^{(6)}$ The variance was chosen as a summary measure of the variability in order to exploit its statistical properties. In fact, variance-based methods are model independent as the sensitivity measure is model free and make it possible to appreciate the nonlinear interactions between factors, 
which is not the case, for example, for the ANOVA, where a linear relationship between the inputs and the output is assumed. Let us consider a model $f$, its response $Y$, and its factors $X_{i}$, with $Y=f\left(X_{1}\right.$, $\left.X_{2}, \ldots, X_{k}\right)$. Sensitivity indices are related to the decomposition of $Y$ into terms related either to each $X_{i}$ taken singularly (first-order indices) or to the cooperative effects of more than one $X_{i}$ (total indices). ${ }^{(7)}$

The variance-based methods were first employed by chemists in the early 1970s, ${ }^{(8)}$ who proposed conditional variances for a sensitivity analysis based on first-order effects only. Their method FAST (Fourrier amplitude sensitivity test) had limited success mainly because of the difficulty in encoding it. ${ }^{(6)}$ Sobol $^{(9)}$ was inspired by these works and proposed a straightforward Monte-Carlo-based implementation of the concept, capable of computing sensitivity measures for arbitrary groups of factors. Several methods are now available to compute these indices ${ }^{(10)}$ but we chose the Saltelli variance-based $\operatorname{method}^{(7)}$ because it requires less simulations compared to other methods.

The aim of this study was to use this method to perform a SA applied to a contamination assessment model of Listeria monocytogenes in cold smoked vacuum packed salmon to identify the subset of the inputs that substantially impact the concentration of the pathogen at consumption. A refined sensitivity analysis was then performed on these important factors to rank them according to their impact on salmon contamination.

\section{MATERIALS AND METHODS}

\subsection{The Contamination Assessment Model: $L$. monocytogenes in Cold Smoked Salmon}

The model used in this study is a contamination assessment model for L. monocytogenes in cold smoked vacuum packed salmon. It evaluates the pathogen contamination of portions at the end of the food shelf life assuming an initial contamination level below 20 cells per portion.

The model is presented in Fig. 1 and is composed of a secondary model, which calculates the effects of the environmental conditions ( $\mathrm{pH}$, temperature, and water activity) on the maximum growth rate, $\mu_{\max }$, and a primary model, which computes the final contamination level, $Y$, given the secondary model output $\left(\mu_{\max }\right)$, the initial contamination level $x_{0}$, and the initial physiological state of the microorganisms $K$. Two approaches were considered. The first and com- monly used approach is a populational approach in which all the contaminating cells located in a particular food portion are supposed to have the same initial physiological state $K$ and their growth is modeled globally. The second approach is a cellular approach in which each cell contaminating a portion is characterized by a specific physiological state $k_{\mathrm{i}}$, which is deduced from the populational physiological state $K$ by sampling in an extreme value type II distribution $\operatorname{EVII}(a, b):^{(11,12)}$

$$
a=E[k]-\frac{1.1642}{0.3658} \cdot S[k] \text { and } b=\frac{S[k]}{0.3658},
$$

with $S[k]=\exp (1.004 \cdot \ln (E[k])-0.447) \quad$ and $\ln (E[k])=0.0103 \cdot \ln (K)^{5}+0.0065 \cdot \ln (K)^{4}-$ $0.039 \cdot \ln (K)^{3}+0.0586 \cdot \ln (K)^{2}+1.1941 \cdot \ln (K)+$ 0.1549 , where $E[k]$ and $S[k]$ are the expected value and standard deviation of $k$, respectively.

The growth of each cell was thus modeled individually and the final contamination level was estimated as the sum of the population density reached at consumption time by each cell of the initial inoculum.

The tested primary models were those of Rosso et al. ${ }^{(13)}$ (Equation (2)) and Baranyi and Roberts ${ }^{(14)}$ (Equation (3)).

$$
\ln x= \begin{cases}\ln x_{0}, & t \leq K / \mu_{\max } \\ \ln x_{\max }-\ln \left(1+\left(\frac{x_{\max }}{x_{0}}-1\right)\right. & t>K / \mu_{\max } \\ \left.\exp \left(-\mu_{\max }\left(t-K / \mu_{\max }\right)\right)\right), & \end{cases}
$$

$$
\ln x=\ln x_{\max }-\ln \left(1+\left(\frac{x_{\max }}{x_{0}}-1\right) \exp \left(-\mu_{\max } A(t)\right)\right)
$$

$$
\text { with } \begin{aligned}
A(t)= & t+\frac{1}{\mu_{\max }} \ln \left(\exp \left(-\mu_{\max } t\right)+\exp (-K)\right. \\
& \left.-\exp \left(-K-\mu_{\max } t\right)\right)
\end{aligned}
$$

where $x$ (CFU) is the bacterial density at the time $t$ (h), $x_{0}$ (CFU) the initial bacterial density, $x_{\max }$ (CFU) the maximum bacterial density, $\mu_{\max }\left(\mathrm{h}^{-1}\right)$ the maximum specific growth rate, and $K$ the physiological state of L. monocytogenes.

A multiplicative type model based on the gamma concept $\mathrm{t}^{(15)}$ was used as a secondary model to describe the effects of temperature, $T, p H$, and water activity, $a w$, on $\mu_{\max }$. The temperature and $\mathrm{pH}$ effects were modeled by cardinal type models ${ }^{(16)}$ while 


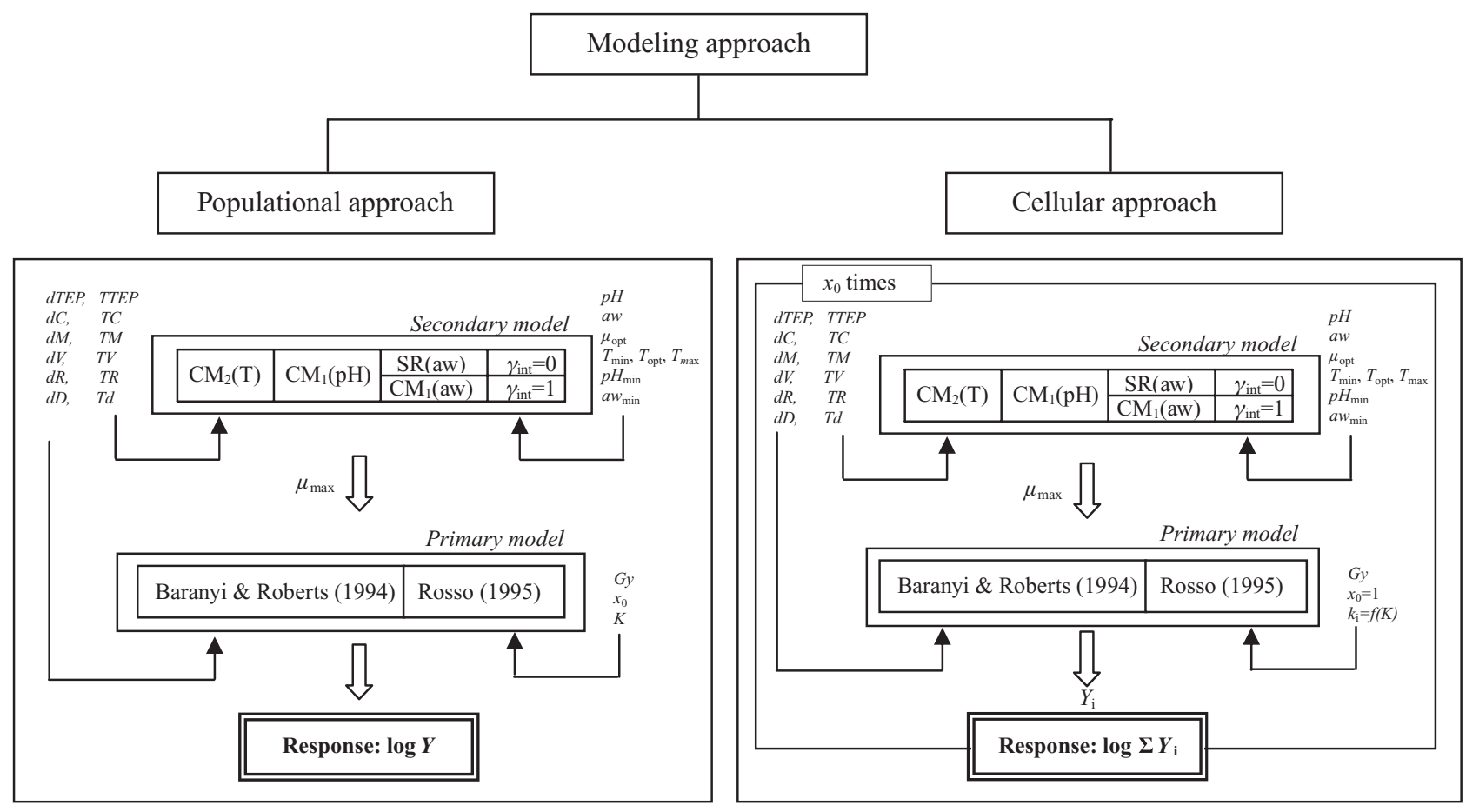

Fig. 1. Diagram of interactions between factors, models, and approaches used in the global sensitivity analysis of the contamination assessment model of L. monocytogenes in cold smoked salmon.

the water activity effect was modeled either by a cardinal type or a square root type model. ${ }^{(17)}$

Finally, the effect of taking the interactions into account was investigated using the interaction terms presented in Augustin et al. ${ }^{(15)}$

$\mu_{\max }=\mu_{\mathrm{opt}} \cdot C M_{2}(T) \cdot C M_{1}(p H) \cdot\left\{\begin{array}{l}S R(a w) \\ S R(a w) \gamma_{\mathrm{int}} \\ C M_{1} \\ C M_{1}(a w) \gamma_{\mathrm{int}}\end{array}\right.$

with

where $X_{\min }, X_{\mathrm{opt}}$, and $X_{\max }$ are the cardinal values of $L$. monocytogenes, $\mu_{\mathrm{opt}}$ is the optimal value of the maximum specific growth rate $\mu_{\max }\left(\mathrm{h}^{-1}\right)$ when $X=$ $X_{\text {opt }}$, and $n$ is a shape parameter $(n=2$ for $T$ and $n=$ 1 for $\mathrm{pH}$ and $a w)$.

The parameters of these models were allowed to vary according to their respective ranges presented in Table I. The range of the physiological parameter, $K$, the increase in the L. monocytogenes population represented by the growth yield, $G y$ ( $x_{\max }$ in Equations (2) and (3) is equal to $x_{0} 10^{G y}$ ), the optimum

$$
\begin{aligned}
& X \leq X_{\min } \\
& X_{\min }<X<X_{\text {max }} \\
& X \geq X_{\max } \\
& S R(a w)= \begin{cases}0, & X \leq X_{\min } \\
\frac{X-X_{\min }}{X_{\mathrm{opt}}-X_{\min }}, & X_{\min }<X \leq X_{\mathrm{opt}}\end{cases} \\
& \gamma_{\mathrm{int}}= \begin{cases}1, & \psi \leq 0.5 \\
2(1-\psi), & 0.5<\psi<1 \quad \psi=\sum_{i} \frac{\varphi(i)}{2 \prod_{j \# 1}(1-\varphi(j))} \quad \varphi(X)=\left(\frac{X_{o p t}-X}{X_{o p t}-X_{\min }}\right)^{3},\end{cases}
\end{aligned}
$$




\begin{tabular}{|c|c|c|}
\hline Factors & Description & Range \\
\hline \multicolumn{3}{|c|}{ Microbiological parameters } \\
\hline$K$ & Physiological state of L. monocytogenes & $0-8$ \\
\hline$x_{0}(\mathrm{CFU})$ & Initial contamination level & $1-20$ \\
\hline Gy $(\log \mathrm{CFU})$ & Growth yield of the L. monocytogenes population & 4-6 \\
\hline$\mu_{\mathrm{opt}}\left(h^{-1}\right)$ & $\begin{array}{l}\text { Optimum specific growth rate of } L \text {. monocytogenes } \\
\text { in cold smoked salmon }\end{array}$ & $0.60-1.30$ \\
\hline$p H$ & Cold smoked salmon pH & $5.3-6.3$ \\
\hline aw & Cold smoked salmon aw & $0.925-0.995$ \\
\hline$T_{\min }\left({ }^{\circ} \mathrm{C}\right)$ & $\begin{array}{l}\text { L. monocytogenes minimum temperature for } \\
\text { growth }\end{array}$ & $-2.8-0.6$ \\
\hline$T_{\text {opt }}\left({ }^{\circ} \mathrm{C}\right)$ & L. monocytogenes optimum temperature for growth & $36.4-40.0$ \\
\hline$T_{\max }\left({ }^{\circ} \mathrm{C}\right)$ & $\begin{array}{l}\text { L. monocytogenes maximum temperature for } \\
\text { growth }\end{array}$ & $40.5-46.1$ \\
\hline$p H_{\min }$ & L. monocytogenes minimum $\mathrm{pH}$ for growth & $3.9-4.5$ \\
\hline$a w_{\min }$ & L. monocytogenes minimum aw for growth & $0.901-0.943$ \\
\hline \multicolumn{3}{|c|}{ Distribution chain parameters } \\
\hline$d T E P(\mathrm{~h})$ & Duration of transport and storage & $4-96$ \\
\hline $\operatorname{TTEP}\left({ }^{\circ} \mathrm{C}\right)$ & Temperature of transport and storage & $-2-7$ \\
\hline$d C(\mathrm{~h})$ & Duration of storage in cold rooms & $0-48$ \\
\hline$T C\left({ }^{\circ} \mathrm{C}\right)$ & Temperature of storage in cold rooms & $1-7$ \\
\hline$d M(\mathrm{~h})$ & Duration of storage at retail & $2-288$ \\
\hline$T M\left({ }^{\circ} \mathrm{C}\right)$ & Temperature of storage at retail & $2-9$ \\
\hline$d V(\mathrm{~h})$ & Duration of the journey back home & $0.1-2.5$ \\
\hline$T V\left({ }^{\circ} \mathrm{C}\right)$ & Temperature of the journey back home & 6-20 \\
\hline$d R(\mathrm{~h})$ & Duration of the storage in the refrigerator & $0-336$ \\
\hline$T R\left({ }^{\circ} \mathrm{C}\right)$ & Temperature of the storage in the refrigerator & $2-12$ \\
\hline$d D(\mathrm{~h})$ & $\begin{array}{l}\text { Duration of unrefrigerated storage before } \\
\text { consumption }\end{array}$ & $0-16$ \\
\hline$T D\left({ }^{\circ} \mathrm{C}\right)$ & $\begin{array}{l}\text { Temperature of unrefrigerated storage before } \\
\text { consumption }\end{array}$ & $10-25$ \\
\hline \multicolumn{3}{|l|}{ Modeling alternatives } \\
\hline Primary models & Baranyi or Rosso & $1-2$ \\
\hline Secondary models & $\begin{array}{l}\text { Cardinal or SR effect of the aw with and without } \\
\text { interactions }\end{array}$ & $1-4$ \\
\hline Approach & Populational or cellular & $1-2$ \\
\hline
\end{tabular}

Table I. Identification and Range of Variations of the Contamination Assessment Model Parameters specific growth rate in cold smoked salmon, $\mu_{\mathrm{opt}}$, and the physicochemical characteristics of the food, $p H$ and $a w$, were obtained directly from experimental data and corresponded to the minimum and maximum observed values. The range of variation of the cardinal values for temperature, $p H$, and $a w$ corresponded to the 1st and 99th percentiles of the distributions kindly provided by the Sym'Previus program. Finally, the range of variation of the distribution chain parameters was obtained from a French study on the temperatures encountered by cold smoked salmon in the distribution chain. ${ }^{(18)}$

To run the contamination assessment model, the differential forms of the primary models were solved numerically with the Runge-Kutta method using the ode23 function of the Matlab software v7.3.0 (The MathWorks Inc., Natick, MA, USA).

\subsection{Global Sensitivity Analysis}

The Saltelli ${ }^{(7)}$ method is based on a numerical procedure for computing the full set of first-order indices, $S_{i}$, and total effect indices, $S t_{i}$, for all the factors $i(i=1, \ldots, k)$ of the studied model.

In this method, two matrices $A$ and $B$ of $N$ lines corresponding to the $N$ simulation runs and $k$ columns corresponding to the $k$ studied factors are first filled with numbers provided by a spacefilling design, for instance, a Latin hypercube sampling (LHS) was used in this study ${ }^{(19)}$ with respect to the range of variation of each factor. Then, $k$ matrices $C_{\mathrm{i}}, i=1, \ldots, k$, containing all the columns of $B$ but the column $i$, which is replaced by the $i^{\text {th }}$ column of matrice $A$, are generated and the contamination assessment model is run on each row of the $k+2$ 
matrices to provide $k+2$ vectors $Y_{A}, Y_{B}$, and $Y_{C i}$. First-order and total effect indices are then calculated with the following formula: ${ }^{(7)}$

$$
\begin{gathered}
S_{i}=\frac{\frac{1}{N} \sum_{u=1}^{N} Y_{A}^{(u)} Y_{C_{i}}^{(u)}-g_{0}}{\frac{1}{N} \sum_{u=1}^{N} Y_{A}^{(u)} Y_{A}^{(u)}-f_{0}^{2}} \\
S t_{i}=1-\frac{\frac{1}{N} \sum_{u=1}^{N} Y_{B}^{(u)} Y_{C_{i}}^{(u)}-f_{0}^{2}}{\frac{1}{N} \sum_{u=1}^{N} Y_{A}^{(u)} Y_{A}^{(u)}-f_{0}^{2}}
\end{gathered}
$$

with

$$
\begin{array}{ll}
f_{0} & \frac{1}{N} \sum_{u=1}^{N} Y_{A}^{(u)} \\
g_{0} & \frac{1}{N} \sum_{u=1}^{N} Y_{A}^{(u)} Y_{B}^{(u)}
\end{array} .
$$

The bootstrap method ${ }^{(20)}$ was used to assess the confidence intervals of these indices through reliable estimates without additional computational effort. ${ }^{(21)}$ In fact, values obtained for the response vectors were sampled with replacement for $10^{4}$ bootstrap replicates and for each replicate, the indices $S_{i}$ and $S t_{i}$ were calculated, leading to a bootstrap estimate of the distribution of the sensitivity indices. Finally, the $95 \%$ confidence intervals of the indices were defined using the 2.5 th and 97.5 th percentiles ${ }^{(21)}$ and were used to indentify the most important factors as the inputs for which total effect indices were significantly different from 0 .

In this study, the effects of $k=26$ factors $(23$ quantitative and 3 qualitative factors) were investigated (Table I) using $N=5 \times 10^{4}$ simulation runs.

Moreover, the effects of the choice of the model response as well as the number of the simulation runs (LHS size) on the SA results were investigated by repeating the analysis while applying the following changes. To investigate the effects of the choices of the model response, the results were first expressed in $\log$ CFU and then without the log transformation (in CFU). Finally, to study the effect of the LHS size, results obtained with the initial LHS size $N=5 \times 10^{4}$ simulations were compared to those obtained with $10^{4}$ runs LHS.

\subsection{Refined Sensitivity Analysis}

The refined sensitivity analysis is also a global sensitivity analysis but its principle is different from that used in the variance-decomposition-based methods. The objective of the refined sensitivity method is to rank the factors that were identified as important factors by the SA.

These factors were therefore sampled in their marginal distributions presented in Table III while noninfluential factors were fixed to the median values of their respective ranges of variations presented in Table I. The contamination assessment model was then run on $10^{4}$ simulations.

The distribution of the output was analyzed according to three methods: ANOVA, Spearman correlation coefficient (SCC), and partial least squares regression (PLSR). To perform the ANOVA, the values of the factors were transformed into 11 classes according to their respective 10th percentiles before performing the analysis using the anovan function of the Matlab software. The obtained $p$-values and $F$ statistics were used to rank the factors. The SCC analysis was performed using the corr function of the Matlab software and the absolute value of the correlation coefficients were used to rank the factors. The PLSR was performed using the SIMCAP9.0 software (UMETRICS AB, Umea, Sweden, www.umetrics.com). PLSR is a powerful method, well known in the chemometrics field ${ }^{(22)}$ for its numerous advantages, which are fully described in the literature. ${ }^{(23-25)}$

The PLSR provides variable influence in projection (VIP) statistics, which were used to calculate PLSR-based sensitivity indices $S I-V I P_{k}$ for each factor $k$, using the following formula:

$$
S I-V I P_{k}=100 \frac{V I P_{k}^{2}}{p},
$$

where $p$ is the total number of factors and their twofactor interactions (here $p=65$ ).

These PLS-based indices were first proposed in Schwob et al., ${ }^{(23)}$ who provided a complete description of the method. A full definition of VIP needs a brief recall on PLSR, which is given in the Appendix. This method is only applicable when the ranges of variation of the inputs are narrow. This is typically the case in the refined sensitivity analysis where important factors identified by the global SA are sampled among their respective distribution.

The important factors were thus finally ranked based on the refined sensitivity analysis indices. 
Table II. Estimates of the First-Order $\left(S_{i}\right)$ and Total Effect $\left(S t_{i}\right)$ Indices of the Sensitivity Analysis and Their Bootstrap 95\% Confidence Intervals Obtained on the Log of the Bacterial Contamination with Different LHS Sizes $\left(N=5 \times 10^{4}\right.$ and $\left.N=10^{4}\right)$

\begin{tabular}{|c|c|c|c|c|}
\hline \multirow[b]{2}{*}{ Factors } & \multicolumn{2}{|c|}{$N=5 \times 10^{4}$} & \multicolumn{2}{|c|}{$N=10^{4}$} \\
\hline & $S t_{i}$ & $S_{i}$ & $S t_{i}$ & $S_{i}$ \\
\hline$a w$ & $0.50[0.47,0.54]$ & $0.31[0.30,0.32]$ & $0.49[0.41,0.57]$ & $0.29[0.26,0.31]$ \\
\hline$T R$ & $0.15[0.11,0.19]$ & $0.06[0.05,0.07]$ & $0.19[0.10,0.28]$ & $0.10[0.08,0.12]$ \\
\hline$d R$ & $0.12[0.08,0.16]$ & $0.05[0.05,0.06]$ & $0.16[0.07,0.25]$ & $0.08[0.06,0.10]$ \\
\hline$K$ & $0.07[0.03,0.12]$ & $0.03[0.03,0.04]$ & $0.09[0.03,0.22]$ & $0.05[0.04,0.07]$ \\
\hline$\mu_{\mathrm{opt}}$ & $0.07[0.03,0.11]$ & $0.01[0.01,0.02]$ & $0.06[-0.03,0.16]$ & $0.03[0.02,0.05]$ \\
\hline$a w_{\min }$ & $0.06[0.02,0.10]$ & $0.02[0.02,0.03]$ & $0.06[-0.03,0.16]$ & $0.01[0.00,0.02]$ \\
\hline$T_{\min }$ & $0.06[0.01,0.10]$ & $0.02[0.02,0.03]$ & $0.05[-0.05,0.14]$ & $0.03[0.01,0.04]$ \\
\hline$x_{0}$ & $0.05[0.01,0.10]$ & $0.04[0.04,0.05]$ & $0.05[-0.05,0.14]$ & $0.03[0.02,0.04]$ \\
\hline$T M$ & $0.05[0.01,0.09]$ & $0.02[0.01,0.02]$ & $0.04[-0.05,0.14]$ & $0.02[0.01,0.04]$ \\
\hline$d M$ & $0.05[0.01,0.09]$ & $0.02[0.01,0.02]$ & $0.05[-0.05,0.15]$ & $0.02[0.01,0.03]$ \\
\hline$p H$ & $0.04[0.00,0.08]$ & $0.02[0.01,0.02]$ & $0.05[-0.05,0.14]$ & $0.01[0.00,0.02]$ \\
\hline$T_{\mathrm{opt}}$ & $0.02[-0.02,0.07]$ & $0.01[0.00,0.01]$ & $0.01[-0.09,0.11]$ & $0.00[-0.01,0.01]$ \\
\hline Gy & $0.02[-0.03,0.06]$ & $0.00[0.00,0.00]$ & $0.01[-0.09,0.10]$ & $0.00[-0.01,0.00]$ \\
\hline$T_{\max }$ & $0.01[-0.03,0.06]$ & $0.00[0.00,0.01]$ & $0.00[-0.10,0.09]$ & $0.01[0.00,0.01]$ \\
\hline$d D$ & $0.01[-0.03,0.06]$ & $0.00[0.00,0.00]$ & $0.01[-0.09,0.10]$ & $0.00[0.00,0.01]$ \\
\hline$T D$ & $0.01[-0.03,0.05]$ & $0.00[0.00,0.00]$ & $0.00[-0.10,0.10]$ & $0.00[0.00,0.01]$ \\
\hline$p H_{\min }$ & $0.01[-0.03,0.05]$ & $0.00[0.00,0.00]$ & $0.00[-0.10,0.09]$ & $0.00[0.00,0.00]$ \\
\hline TTEP & $0.01[-0.04,0.05]$ & $0.00[0.00,0.00]$ & $0.00[-0.09,0.10]$ & $0.00[-0.01,0.00]$ \\
\hline$T C$ & $0.01[-0.04,0.05]$ & $0.00[0.00,0.00]$ & $0.00[-0.10,0.09]$ & $0.00[0.00,0.00]$ \\
\hline$d C$ & $0.01[-0.04,0.05]$ & $0.00[0.00,0.00]$ & $0.00[-0.10,0.09]$ & $0.00[0.00,0.00]$ \\
\hline$d T E P$ & $0.01[-0.04,0.05]$ & $0.00[0.00,0.00]$ & $0.00[-0.10,0.09]$ & $0.00[0.00,0.00]$ \\
\hline Approach & $0.01[-0.04,0.05]$ & $0.00[0.00,0.00]$ & $0.01[-0.09,0.11]$ & $0.00[-0.01,0.00]$ \\
\hline$T V$ & $0.01[-0.04,0.05]$ & $0.00[0.00,0.00]$ & $-0.01[-0.10,0.09]$ & $0.00[0.00,0.00]$ \\
\hline$d V$ & $0.01[-0.04,0.05]$ & $0.00[0.00,0.00]$ & $-0.01[-0.10,0.09]$ & $0.00[0.00,0.00]$ \\
\hline Primary models & $0.01[-0.04,0.05]$ & $0.00[0.00,0.00]$ & $-0.01[-0.11,0.09]$ & $0.00[0.00,0.00]$ \\
\hline Secondary models & $0.01[-0.04,0.05]$ & $0.00[0.00,0.00]$ & $0.01[-0.08,0.11]$ & $0.00[-0.01,0.01]$ \\
\hline
\end{tabular}

\section{RESULTS}

\subsection{Sensitivity Analysis}

The SA results obtained after a log transformation of the bacterial contamination are depicted in Table II where the first order and total effect indices of the factors are presented with their confidence bootstrap intervals.

The 26 factors were ranked according to their total effect indices obtained with $5 \times 10^{4}$ runs LHS. Based on their confidence intervals, 10 factors composed the subset of important factors, namely, the salmon water activity, $a w$, the temperature, $T R$, and duration, $d R$, of the storage in the domestic refrigerator, the initial physiological state, $K$, the optimum growth rate, $\mu_{\mathrm{opt}}$, the minimum water activity for growth, $a w_{\min }$, the minimum temperature for growth, $T_{\min }$, the initial contamination level, $x_{0}$, and the temperature, $T M$, and the duration, $d M$, of the storage at retail. Besides, the parameters $d R, T_{\min }, x_{0}, d M$, and $T M$ were previously identified by Pouillot et al. ${ }^{(26)}$ in the top 5 of the most important factors influencing the exposure assessment model of L. monocytogenes in cold smoked salmon.

The values of the indices obtained with the $10^{4}$ runs LHS were very similar to those obtained with $5 \times 10^{4}$ runs LHS. For example, for the factor $a w, S t_{i}$ values of 0.50 and 0.49 and $S_{i}$ values of 0.31 and 0.29 were obtained for the $5 \times 10^{4}$ runs LHS and the $10^{4}$ runs LHS, respectively. However, larger confidence intervals were obtained with the $10^{4}$ runs LHS, especially for the total effect indices, which mean that if the analysis was based on the $10^{4}$ LHS design, the factors $\mu_{\mathrm{opt}}, a w_{\min }, T M, d M, T_{\min }$, and $x_{0}$ would not have been identified as important factors.

To study the effect of the type of response on the results, the SA was also performed directly on the bacterial contamination without applying the log transformation. Fig. 2 presents the subsets of important inputs when the SA was performed on the bacterial contamination or on the log of the bacterial contamination for $5 \times 10^{4}$ runs LHS. Fig. 2 shows that the subset of important factors was different in case the log transformation was applied to 

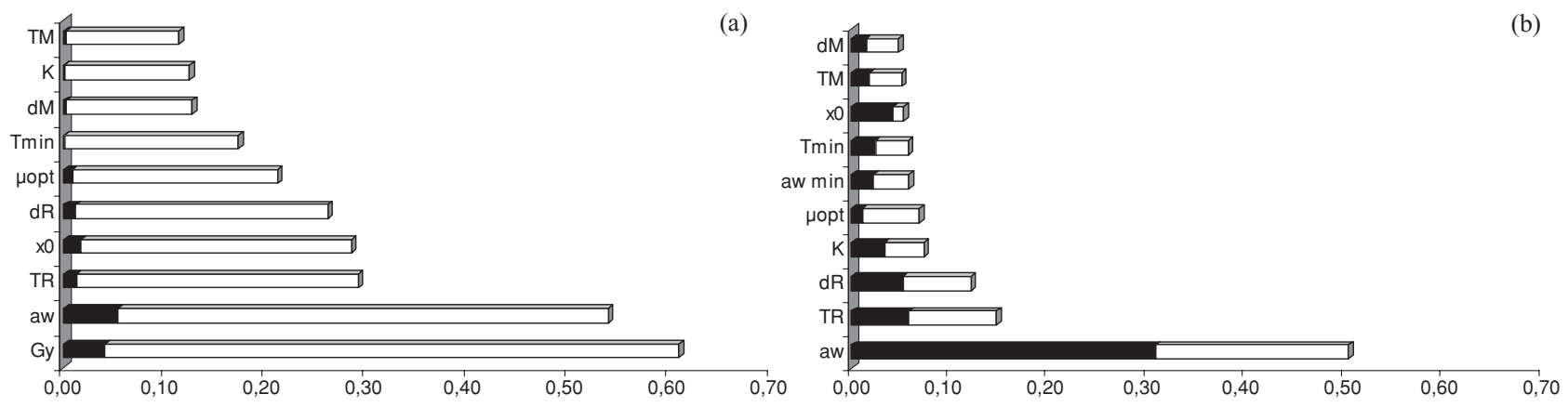

Fig. 2. Indices $S_{i}$ (black bars) and $S t_{i}$ (white bars) obtained for the sensitivity analysis when applied to (a) the bacterial contamination or (b) the log of the bacterial contamination using a $5 \times 10^{4}$ runs LHS.

the model response before the SA was performed. In fact, when applying the SA directly to the L. monocytogenes contamination (in CFU) (Fig. 2a), the growth yield, $G y$, appeared to be the most important factor $\left(S t_{i}=0.61\right)$ while it was not identified in the subset of important factors when applying the SA to the $\log$ of the L. monocytogenes contamination (in $\log$ CFU) (Fig. 2b). Besides, the factor $a w_{\min }$ was part of the subset of important factors only when considering the $\log$ of the bacterial contamination. Thus, the identification of the most important factors relies both on the LHS size and on the choice of the model response.

\subsection{Refined Sensitivity Analysis}

Table III presents the values assigned to nonimportant factors and the distributions associated with the most influent factors used in the refined sensitivity analysis applied to the log of the bacterial contamination.

The results of the ANOVA proved that all the tested factors had significant impact on the log of the response as all the $p$-values were inferior to the 0.05 threshold. The $F$-statistic was then used to rank the factors. The rankings obtained by the ANOVA, the SCC, and the PLSR are depicted in Table IV, which shows close rankings of the factors whatever the method used. Thus, the five most important factors are the domestic refrigerator storage duration, $d R$, and temperature, $d T$, the physiological parameter, $K$, the optimum growth rate, $\mu_{\text {opt }}$, and the duration of the storage at retail, $d M$. Moreover, we noticed that the ranking obtained using the ANOVA method was very close to that obtained with PLSR. The results of the PLSR are depicted in Fig. 3 where the sensitivity indices SI-VIP of the studied factors (simple and quadratic effects) and their interactions are presented. These PLSR-based sensitivity indices represent the major advantage of the PLSR method as the assessment of the effects of the interactions between factors is not possible with the two other methods. The most important interaction was obtained between the temperature, $T R$, and the duration, $d R$, of the domestic storage in the refrigerator and this interaction was ranked at the 6th position in the PLSR refined sensitivity analysis, while the interaction between the duration and temperature of the storage at retail was ranked at the 9th position, before the factors $T_{\min }, a w_{\min }$, and $x_{0}$, and followed by the interactions involving factors $K$ and $\mu_{\mathrm{opt}}$.

\section{DISCUSSION}

Total effect indices and first-order indices are especially powerful when performing SA in case of nonadditive and nonlinear models, ${ }^{(21)}$ such as the contamination assessment model used in this study. In fact, as shown in Table II, the sum of the first-order indices $\left(S_{i}\right)$, which account for the individual contribution of each factor into the variance of the output, is less than 1 (0.77), which means that the variance of the output cannot be only explained by the sum of the individual effects of each factor but is also attributed to the effects of interactions and the use of the variance-based sensitivity analysis is therefore fully justified.

This is also confirmed by the relatively important difference observed between the $S t_{i}$ and the $S_{i}$ for all the important factors. For example, for the cold smoked salmon $a w$, the difference between the $S t_{i}$ $(0.5)$ and the $S_{i}(0.3)$ flags an important role of interactions. The factors temperature, $T R$, and duration, $d R$, of the domestic refrigerator storage were also 


\begin{tabular}{|c|c|c|}
\hline Factors & Description & Distribution/Value $^{\mathrm{a}}$ \\
\hline \multicolumn{3}{|l|}{ Uncertainty factors } \\
\hline $\log K$ & Physiological state of L. monocytogenes & $N(0.67,1.23)$ \\
\hline$x_{0}(\mathrm{CFU})$ & Initial contamination level & $P T(10,1, \infty)$ \\
\hline$\mu_{\mathrm{opt}}\left(h^{-1}\right)$ & Optimum specific growth rate & $N T(0.924,0.286,0, \infty)$ \\
\hline aw & Cold smoked salmon aw & $N(0.960,0.006)$ \\
\hline$T_{\min }\left({ }^{\circ} \mathrm{C}\right)$ & $\begin{array}{l}\text { L. monocytogenes minimum } \\
\text { temperature for growth }\end{array}$ & $N(-1.08,0.72)$ \\
\hline$a w_{\min }$ & $\begin{array}{l}\text { L. monocytogenes minimum aw for } \\
\text { growth }\end{array}$ & $N(0.922,0.009)$ \\
\hline$d M(\mathrm{~h})$ & Duration of storage at retail & $E(120)$ \\
\hline$T M\left({ }^{\circ} \mathrm{C}\right)$ & Temperature of storage at retail & $N(5.5,2.0)$ \\
\hline$d R(\mathrm{~h})$ & $\begin{array}{l}\text { Duration of the storage in the } \\
\text { refrigerator }\end{array}$ & $E(120)$ \\
\hline$T R\left({ }^{\circ} \mathrm{C}\right)$ & $\begin{array}{l}\text { Temperature of the storage in the } \\
\text { refrigerator }\end{array}$ & $N(7.0,3.0)$ \\
\hline \multicolumn{3}{|l|}{ Fixed factors } \\
\hline$p H$ & Cold smoked salmon $\mathrm{pH}$ & 5.8 \\
\hline Gy $(\log \mathrm{CFU})$ & $\begin{array}{l}\text { Increase in the L. monocytogenes } \\
\text { population }\end{array}$ & 5 \\
\hline$T_{\text {opt }}\left({ }^{\circ} \mathrm{C}\right)$ & $\begin{array}{l}\text { L. monocytogenes optimum } \\
\text { temperature for growth }\end{array}$ & 38.0 \\
\hline$T_{\max }\left({ }^{\circ} \mathrm{C}\right)$ & $\begin{array}{l}\text { L. monocytogenes maximum } \\
\text { temperature for growth }\end{array}$ & 42.5 \\
\hline$p H_{\min }$ & $\begin{array}{l}\text { L. monocytogenes minimum } \mathrm{pH} \text { for } \\
\text { growth }\end{array}$ & 4.2 \\
\hline$d T E P(\mathrm{~h})$ & Duration of transport and storage & 50.0 \\
\hline $\operatorname{TTEP}\left({ }^{\circ} \mathrm{C}\right)$ & Temperature of transport and storage & 2.5 \\
\hline$d C(\mathrm{~h})$ & Duration of storage in cold rooms & 24.0 \\
\hline$T C\left({ }^{\circ} \mathrm{C}\right)$ & Temperature of storage in cold rooms & 4.0 \\
\hline$d V(\mathrm{~h})$ & Duration of the journey back home & 1.3 \\
\hline$T V\left({ }^{\circ} \mathrm{C}\right)$ & Temperature of the journey back home & 13.0 \\
\hline$d D(\mathrm{~h})$ & $\begin{array}{l}\text { Duration of unrefrigerated storage } \\
\text { before consumption }\end{array}$ & 8.0 \\
\hline$T D\left({ }^{\circ} \mathrm{C}\right)$ & $\begin{array}{l}\text { Temperature of unrefrigerated storage } \\
\text { before consumption }\end{array}$ & 17.5 \\
\hline Primary models & Baranyi or Rosso & Rosso \\
\hline Secondary models & $\begin{array}{l}\text { Cardinal or SR effect of the aw with and } \\
\text { without interactions }\end{array}$ & SR without interactions \\
\hline Approach & Populational or cellular & Populational \\
\hline
\end{tabular}

${ }^{\mathrm{a}} N(m, s)$, normal distribution with expected value $m$ and standard deviation $s ; P T(m, a, b)$, Poisson distribution with expected value $m$ truncated on $[a, b] ; N T(m, s, a, b)$, normal distribution with expected value $m$ and standard deviation $s$ truncated on $[a, b] ; E(m)$, exponential distribution with expected value $m$. identified as influential factors. The importance of the consumer link in the cold chain was previously reported $^{(26)}$ and this study quantitatively confirms this observation. Besides, the factors $\mu_{\mathrm{opt}}, T_{\min }$, and $x_{0}$, also identified as important factors in this study, were previously ranked among important factors impacting the response of similar models in the same food product. ${ }^{(26)}$ The modeling approach choice (cellular or populational) was ranked among the less important factors in the framework of this contamination assessment. The same result was also observed in a previous study made for L. monocytogenes in pâté stored at $7{ }^{\circ} \mathrm{C} .(27)$ Unlike the authors of that study, who used a very small range of variation for the cellular physiological states $k_{i}$ and studied a unique temperature for growth $\left(7^{\circ} \mathrm{C}\right)$, our work explored a larger range of variations for $k_{i}$ and tested several storage scenarios with different temperatures. Yet both analyses came out with the same conclusion. However, the lack of significant impact of the modeling approach in these two cases must not be extrapolated to all situations. In fact, in some exposure 
Table IV. Ranking of the Contamination Assessment Model Factors Using the ANOVA, SCC, and PLSR Refined Sensitivity Analyses Applied on the Log of the Bacterial Contamination

\begin{tabular}{lccc}
\hline Factors & ANOVA & SCR & PLSR \\
\hline$d R$ & 1 & 2 & 1 \\
$K$ & 2 & 1 & 3 \\
TR & 3 & 5 & 4 \\
$\mu_{\text {opt }}$ & 4 & 3 & 5 \\
$d M$ & 5 & 4 & 2 \\
TM & 6 & 8 & 7 \\
$a w$ & 7 & 7 & 6 \\
$T_{\min }$ & 8 & 9 & 8 \\
$a w_{\min }$ & 9 & 10 & 9 \\
$x_{0}$ & 10 & 6 & 10 \\
\hline
\end{tabular}

assessment models, it could indeed have an important effect.

Moreover, the SA showed that the initial physiological state of the cells, $K$, was twice as important as $x_{0}$. However, this factor is scarcely used in QMRA, leading to fail safe but incorrect predictions. We therefore recommend a better characterization of this factor to improve model predictions.

All of these factors were also identified as important factors when the response model was changed, considering the bacterial contamination without ap- plying the log transformation. However, a new factor, the growth yield, $G y$, was added to the list of important factors. Moreover, the values of the indices were changed and the contribution of the first-order indices was less important, relating an increased effect of the interactions. It seems therefore crucial to identify the most appropriate model response before applying the SA. In the case of risk assessment, for example, where the prevalence and the number of cells are of paramount importance, especially for the dose-response model, it may be more relevant to consider the final cell number when applying the SA. In this case, the SA will identify factors influencing high and risky final contaminations. However, when contamination assessment models are used to estimate the probability to exceed low contamination thresholds (e.g., $100 \mathrm{CFU} / \mathrm{g}$ in the case of L. monocytogenes to fulfill the EU regulation regarding the ready-to-eat foods allowing the growth of the pathogen $\left.{ }^{(28)}\right)$, the $\log$ transformation will give more importance to low contamination levels and SA will more accurately identify factors influencing these low contamination levels.

In this framework, the effect of the LHS size was also investigated. When the analysis was performed on $10^{4}$ runs LHS, the calculated indices were almost the same as those calculated with $5 \times 10^{4}$ runs LHS

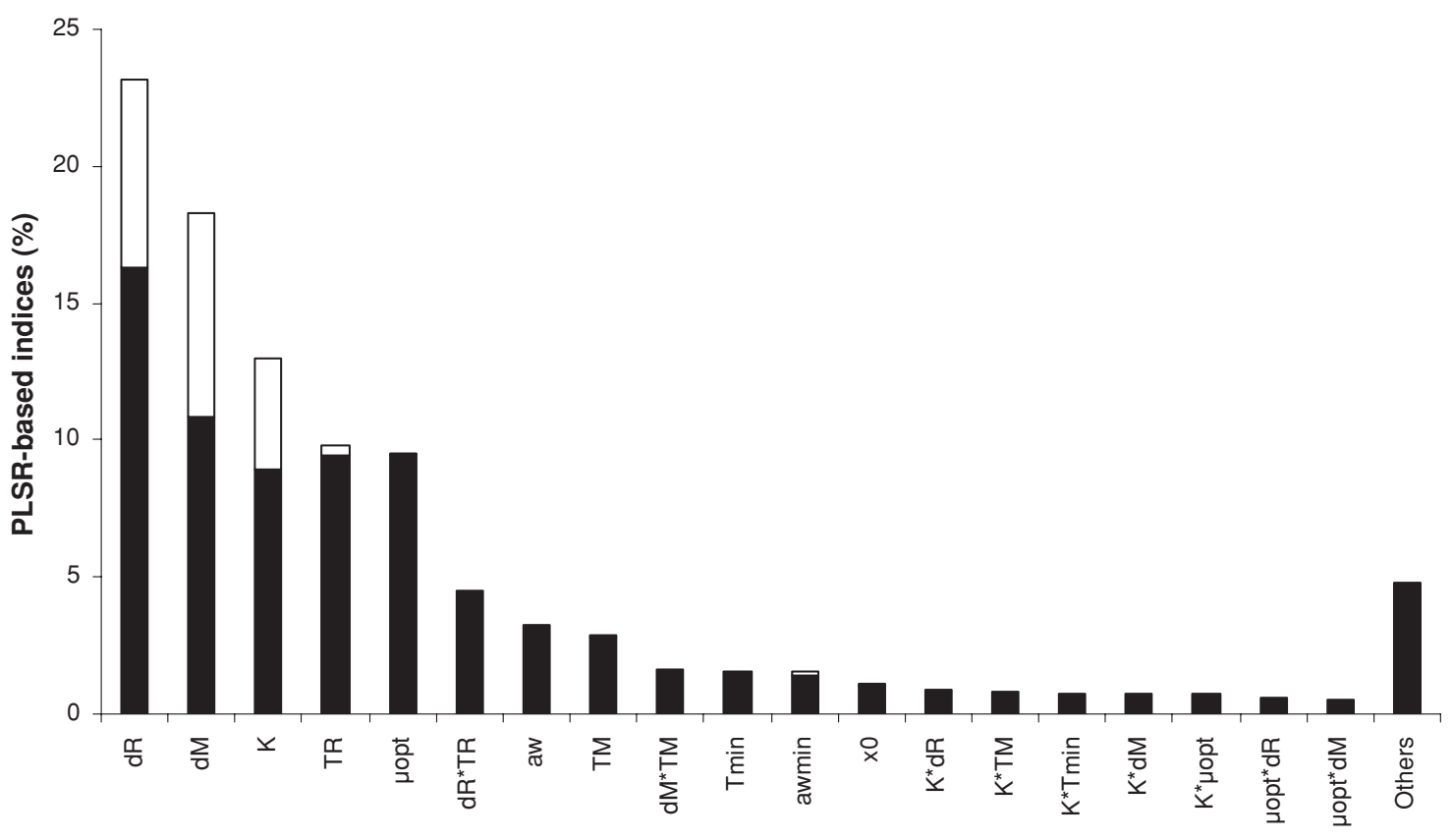

Fig. 3. VIP-based sensitivity indices associated with the quadratic (white bars) and simple (black bars) effects of the important factors and their interactions. Interactions with uncertainty indices $<0.5 \%$ were gathered under the item "others." 
but the confidence intervals of the total effect indices, which are used to decide whether the studied factor is influential or not, were wider compared to those obtained with $5 \times 10^{4}$ runs LHS (Table II). On the contrary, the confidence intervals of the first-order effects were not drastically changed. This is, for example, typically the case for the factor $\mu_{\mathrm{opt}}$; the confidence interval for its total effect indice was estimated to be $[-0.03,0.16]$ instead of $[0.03,0.11]$ when using the $5 \times 10^{4}$ runs LHS, while its first-order indice confidence interval was estimated to be $[0.02,0.05]$ when using the $10^{4}$ runs LHS and to be $[0.03,0.04]$ when using the $5 \times 10^{4}$ runs LHS.

Thus, when comparing the lower confidence bound of the first effect indice to the total indice, we observed that the $S_{i}$-bound was superior to the $S t_{i}$-bound, which is by definition impossible since the total effect $S t_{i}$ is the sum of the first-order effect $S_{i}$ plus the interactions effects. This result is incoherent and proves that the LHS size was not appropriate. In fact, when the space filling design is sparse, the estimates of the main effect contribution of each input factor to the variance of the output remains possible and the confidence interval of the first-order indices are not affected; however, the effects of the interactions are poorly assessed, leading to large confidence intervals for the total effect indices and most of the factors that were identified as important factors (because their confidence interval was significantly different from 0 ) were consequently retrieved from the subset of influential factors. Clear decision rules to determine the optimum number of simulations for a given model are unfortunately not available in the literature (few hundreds to few thousands). We therefore propose to test the coherence between the confidence intervals of the total effects to those of the firstorder effects to check if the number of simulations is appropriate.

The refined sensitivity analysis provided a ranking of the important factors (identified by the global sensitivity analysis) when sampled in their marginal distributions. Just like the observation made in the SA results, the duration, $d R$, and the temperature, $T R$, of the storage at the domestic refrigerator were identified as major factors as well as the optimum growth rate, $\mu_{\mathrm{opt}}$, and the physiological state, $K$. However, the aw was ranked 7 th after the effect of the interaction between the duration and the temperature of the storage at the refrigerator. This observation confirms the complementarity between the SA and the refined sensitivity analysis. In the former analysis, numerous factors with large ranges of variations are used and the method is able to iden- tify a group of important factors and provide a primary ranking, while in the latter analysis, a ranking of these factors is proposed using a narrower range of variation for the subset of the identified important factors.

In this study, three refined sensitivity analysis methods were used and the PLSR was introduced and compared to commonly used ANOVA and SCC. The three methods provided similar results, which proves that the PLSR can be used efficiently in QMRA. Moreover, the PLSR provided PLSR-based sensitivity indices expressed in percentages. These are very easy to interpret and account for simple and quadratic effects of the factors and their interactions. For example, if we sum the simple and the quadratic effect of the duration of the domestic storage, $d R$, we can explain $23 \%$ of the response. Similarly the parameter $K$ explains $13 \%$ of the variability of the response. Thus the variability of the top five factors is responsible for $74 \%$ of the variability of the response. More interestingly, this method made it possible to appreciate the effects of the interactions, which explain $16 \%$ of the model response, with the interaction between the duration, $d R$, and the temperature, $T R$, of the domestic storage being the most important ( $5 \%$ of the response).

\section{CONCLUSION}

The aim of this article was to apply the Saltelli global, variance-based sensitivity analysis method ${ }^{(7)}$ to a contamination assessment model involving quantitative and qualitative factors through the example of L. monocytogenes in cold smoked vacuum packed salmon. This method computed first-order indices and total effect indices for each of the factors and made it possible to identify a subset of 10 factors out of 26 as important factors. A refined sensitivity analysis was further performed using the PLSR innovative method. After sampling the important factors in their marginal distribution, a ranking of the most important factors was proposed using PLSR-based indices, taking into account simple and quadratic effects of the factors as well as their interactions with other factors.

The application of the presented global SA and refined sensitivity analysis to other models especially more complex QMRA models is worth conducting to try to simplify them and thus reduce data acquisition costs and provide an efficient tool to orientate risk management decisions and evaluate risk mitigation scenarios. 


\section{ACKNOWLEDGMENTS}

The French program of predictive microbiology Sym'Previus is gratefully acknowledged for providing the cardinal values of $L$. monocytogenes. The authors also thank the Cemagref (Centre National du Machinisme Agricole, du Génie Rural, des Eaux et Forêts) and the ANIA (Association Nationale des Industries Agro-alimentaires) for providing time temperature profiles.

\section{APPENDIX: A BRIEF PRESENTATION OF THE PLSR METHOD}

PLSR is a regression method based on an iterative algorithm. As all other regression methods it provides a regression equation to relate several explanatory factors to a response. However, among many advantages, one of its major advantages is its ability to deal properly with correlated variables. Indeed, and since it is based on a tricky use of partial covariances, it can provide, even with this type of variables, several statistics (regression coefficients, VIP,$\ldots$ ) that can be used, for instance, for measuring the factor effects on the response uncertainty.

Its principle is to construct PLS components, referred to as $t_{h}$, which are linear combinations of the original factors with their relative weights $w_{h j}$. The originality of PLSR is that these weights take into account the response itself. The right number $H$ of PLS components is given by means of a specific crossvalidation test.

Let us define the redundancy between the response $Y$ and a $t_{h}$ component by:

$$
R d\left(Y, t_{h}\right)=\operatorname{cor}^{2}\left(Y, t_{h}\right)
$$

and between the response $Y$ and a set of several $t_{h}$ by:

$$
R d\left(Y, t_{h 1}, \ldots, t_{H}\right)=\sum_{h=1}^{H} \operatorname{cor}^{2}\left(Y, t_{h}\right) .
$$

Then we can define the VIP as:

$$
V I P_{H k}=\left[\frac{p}{R d\left(Y, t_{1}, \ldots, t_{H}\right)} \sum_{l=1}^{H} R d\left(Y, t_{l}\right) w_{l k}^{2}\right]^{1 / 2} \text {. }
$$

\section{REFERENCES}

1. Havelaar AH, Evers EG, Nauta MJ. Challenges of quantitative microbial risk assessment at EU level. Trends in Food Science \& Technology, 2008; 19:S26-S33.

2. Zwietering MH. Quantitative risk assessment: Is more complex always better?-Simple is not stupid and complex is not always more correct. International Journal of Food Microbiology, 2009; 134:57-62.

3. Saltelli A. Sensitivity analysis for importance assessment. Risk Analysis, 2002; 22(3):579-590.

4. Frey HC, Patil SR. Identification and review of sensitivity analysis methods. Risk Analysis, 2002; 22(3):553-578.

5. Membré J-M, Kan-King-Yu D, Blackburn CDW. Use of sensitivity analysis to aid interpretation of a probabilistic Bacillus cereus spore lag time model applied to heat-treated chilled foods (REPFEDs). International Journal of Food Microbiology, 2008; 128:23-33.

6. Saltelli A, Ratto M, Andres T, Campolongo F, Cariboni J, Gatelli D, Saisana M, Tarantola S (eds). Global Sensitivity Analysis: The Primer. Chichester, West Sussex, UK: Wiley, 2008.

7. Saltelli A. Making best use of model evaluations to compute sensitivity indices. Computer Physics Communications, 2002; 145:280-297.

8. Cukier RI, Fortuin CM, Schuler KE, Petschek AG, Schaibly $\mathrm{JH}$. Study of the sensitivity of coupled reaction systems to uncertainties in rate coefficients. Journal of Chemical Physics, 1973; 59:3873-3878.

9. Sobol IM. Global sensitivity indices for non linear mathematical models and their Monte Carlo estimtes. Mathematics and Computers in Simulation, 2001; 55:271-280.

10. Saltelli A, Chan K, Scott EM (eds). Sensitivity Analysis. Chichester, West Sussex, UK: Wiley, 2000.

11. Guillier L, Augustin J-C. Modelling the individual cell lag time distributions of Listeria monocytogenes as a function of the physiological state and the growth conditions. International Journal of Food Microbiology, 2006; 111:241-251.

12. Guillier L, Augustin J-C. Erratum to "Modelling the individual cell lag time distributions of Listeria monocytogenes as a function of the physiological state and the growth conditions". International Journal of Food Microbiology, 2008; 124(1): 114.

13. Rosso L, Bajard S, Flandrois JP, Lahellec C, Fournaud J, Veit $\mathrm{P}$. Differential growth of Listeria monocytogenes at 4 and $8^{\circ} \mathrm{C}$ : Consequences for the shelf life of chilled products. Journal of Food Protection, 1996; 59:944-949.

14. Baranyi J, Roberts TA. A dynamic approach to predicting bacterial growth in food. International Journal of Food Microbiology, 1994; 23(3-4):277-294.

15. Augustin J-C, Zuliani V, Cornu M, Guillier L. Growth rate and growth probability of Listeria monocytogenes in dairy, meat and seafood products in suboptimal conditions. Journal of Applied Microbiology, 2005; 99:1019-1042.

16. Rosso L, Lobry JR, Bajard S, Flandois JP. Convenient model to describe the combined effects of temperature and $\mathrm{pH}$ on microbial growth. Applied and Environmental Microbiology, 1995; 610-616.

17. Ratkowsky DA, Olley J, McMeekin TA, Ball A. Relationship between temperature and growth rate of bacterial cultures. Journal of Bacteriology, 1982; 149:1-5.

18. Morelli E, Derens E. Evolution des températures du saumon fumé au cours des circuits logistiques. Revue Générale du Froid, 2009; 1090:51-56.

19. McKay MD, Beckman RJ Conover WJ. A comparison of three methods for selecting values of input variables in the analysis of output from a computer code. Technometrics, 1979; 21(2):239-245.

20. Efron B, Tibshirani RJ. An Introduction to the Bootstrap. New York: Chapman and Hall, 1993.

21. Archer GEB, Saltelli A Sobol IM. Sensitivity measures, ANOVA-like techniques and the use of bootstrap. Journal of Statistical Computation and Simulation, 1997; 58:99-120.

22. Wold S, Sjöstrom M, Friksson L. PLS Regression: A basic tool of chemometrics. Chemometrics and Intelligent Laboratory Systems, 2001; 58:109-130. 
23. Schwob C, Gauchi J-P, Huiji S, Chambon L. Two efficient sensitivity analysis methods to address factor prioritization in the context of structural computations. Submitted to Reliability Engineering \& Sytem Safety, 2009.

24. Tenenhaus M. La régression PLS, théorie et pratique. Paris: Technip, 1998.

25. Tenenhaus M, Gauchi J-P, Ménardo C. Régression PLS et applications. Revue de Statistique Appliquée, 1995; 53(1):763.

26. Pouillot R, Miconnet N, Afchain AL, Delignette-Muller M-L, Beaufort A, Rosso L, Denis J-B, Cornu M. Quantitative risk assessment of Listeria monocytogenes in French cold-smoked salmon: I. Quantitative exposure assessment. Risk Analysis, 2007; 27:683-700.

27. François K, Devlieghere F, Smet K, Standaert AR, Geeraerd AH, Van Impe JF, Debevere J. Risk Assessment of Listeria monocytogenes: Impact of individual cell variability on the exposure assessment step. Risk Analysis, 2006; 26(1):105-114.

28. Anonymous, Commission Regulation (EC) No. 2073/2005 of 15 November 2005 on microbiological criteria for foodstuffs. Official Journal of the European Union, L 338, 22/12/2005126, 2005. 